\title{
A Case Report and Literature Review:
}

\section{Treacher Collins Syndrome: A Case Report and Review of Literature}

\author{
Effat Khodadadi ${ }^{1}$, Zahra Dehghan ${ }^{2 *}$ (1)
}

1. Department of Pedodontics, School of Dentistry, Babol University of Medical Sciences, Babol, Iran.

2. Department of Dentistry, School of Dentistry, Babol University of Medical Sciences, Babol, Iran.

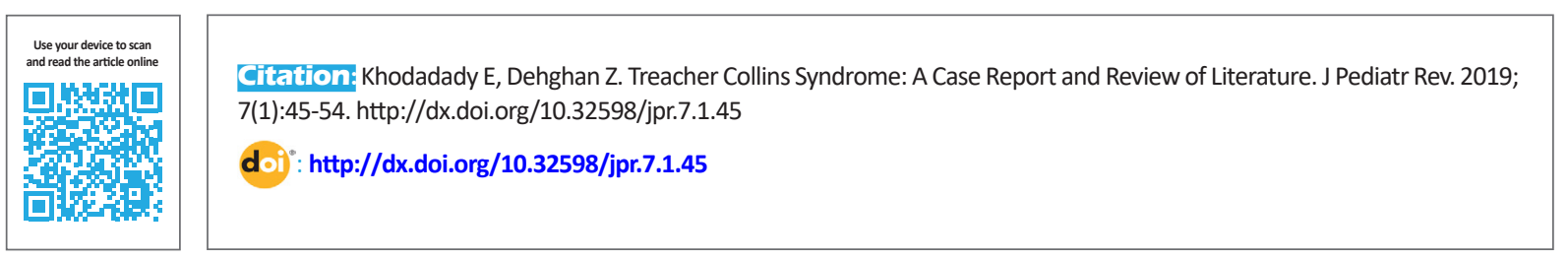

Funding: See Page 53

(c) Copyright: The Author(s)

Article info:

Received: 31 December 2017

First Revision: 07 January 2018

Accepted: 03 March 2018

Published: 01 January 2019

Key Words:

Mandibulofacial

dysostosis, Treacher

Collins Syndrome,

Craniofacial deformities

\begin{abstract}
A B S TRACT
Introduction: Treacher Collins Syndrome (TCS) is an inherited and rare, autosomal dominant condition of craniofacial malformation with varying degrees of penetrance and expression that has been described extensively in the scientific literature with more than 250 cases reported. We presented a 7-year-old boy with TCS. The etiology, clinical features, differential diagnosis and treatment planning have been discussed. In addition, we also reviewed 10 varied cases of TCS.

Case Presentation: Syndromic appearance of abnormal orbits, eyes, ear, and facial bones, along with normal physical and dental development and intelligence quotient were observed in a 7-year old boy referred to the Pediatric Department of Babol Dental School. The patient had no family history of any syndrome, and after reviewing his complete medical records and diagnosing oral and dental problems, the treatment plan was devised. Due to the high risk of caries in the patient, he was followed up every three months.
\end{abstract}

Conclusions: Early detection, treatment and particular attention to every case of TCS can reduce disease symptoms. Psychological consultation can improve the quality of life for these patients.

\section{Introduction}

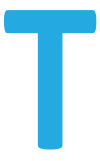

reacher Collins Syndrome (TCS) or mandibulofacial dysostosis is an inherited and rare, autosomal dominant condition of craniofacial malformation with varying degrees of penetrance and expression (1-3). This term is also called "Berry's Syndrome" and "FranceschettiZwahlen-Klein" syndrome because of early recognition by Berry (1889), Treacher Collins (1900) and Franceschet- ti and Klein $(1949)(4,5)$. TCS is a result of interference in the development of the first and second branchial arches. An individual with TCS has a 50\% chance of passing the syndrome to his or her child (6). The symptoms of TCS varies among the affected individuals, ranging from mild and therefore undiagnosed symptoms to severe facial involvement and life-threatening airway compromise (7). The most frequent clinical manifestations are antimongoloid palpebral fissures, malar and mandibular hypoplasia, malformation of auricular pinna, coloboma

* Corresponding Author:

Zahra Dehghan, MD

Address: Department of Dentistry, School of Dentistry, Babol University of Medical Sciences, Babol, Iran.

Tel: +98 (911) 3255722

E-mail: z.dehghan85@gmail.com 
of the lower eyelids, conductive deafness, cleft palate and dental anomalies (4). Early detection and treatment can improve the quality of life of these patients.

\section{Cases Presentation}

A 7-year-old boy with a chief complaint of primary molar pain was referred to the Pediatric Department of Babol Dental School. He was born at term in a healthy family, and the pregnancy of his mother was uncomplicated. The mother also had no history of alcohol, smoking and drug abuse. The patient's facial appearance indicated a specific syndrome. In extra oral examination, hypoplasia of the facial bones such as small and malformed jaws, absent or undeveloped cheek bones as well as the floor and side wall of socket of the eye were noted. In addition, the lower jaw was slanting, and small and external ear anomalies, nasal deformity, sparse eyelashes and lower eyelids were detected (Figure 1). Intraoral examination revealed severe carious lesions of the primary teeth (anterior and posterior), mild periodontitis due to poor oral hygiene and mesial step occlusion (Figure 2).

Panoramic radiographic examination indicated severe caries, but there were no lesions or abnormalities in the teeth or bones (Figure 3). The patient's medical history was obtained from the parents and showed normal physical and dental development and intelligence quotient with no medical or systemic problems. Although there was no case of TCS in the family history, based on clinical and radiographic findings, the patient was diagnosed with TCS. This syndrome was distinguished from others like Miller, Nager and Goldenhar on the basis of 'bird like' or 'sunk-in' appearance, bilateral involvement of facial structures without limb or vertebral abnormalities, and epibulbar dermoids. After completely reviewing the patient's records and diagnosing the oral and dental problems, the treatment plan was devised. The parents were given instructions for oral hygiene and prophylaxis, fluoride therapy, anterior primary teeth extraction, pulpectomy and stainless steel crowns (SScrowns) of primary molars were performed. The patient was then referred to an orthodontist on account of probable crowding due to micrognathia and normal size of permanent teeth. He was rescheduled to visit every three months, because of the high risk of caries.

\section{Discussion and Review of the Literatures}

TCS is caused by mutations in the TCOF1, POLR1C or POLR1D genes that affect facial development before birth. TCOF1 is located on chromosome 5 and encodes the treacle protein (6), and mutations in this gene account for $81 \%$ to $93 \%$ of all TCS cases. POLR1C and POLR1D gene mutations are responsible for $2 \%$ of the
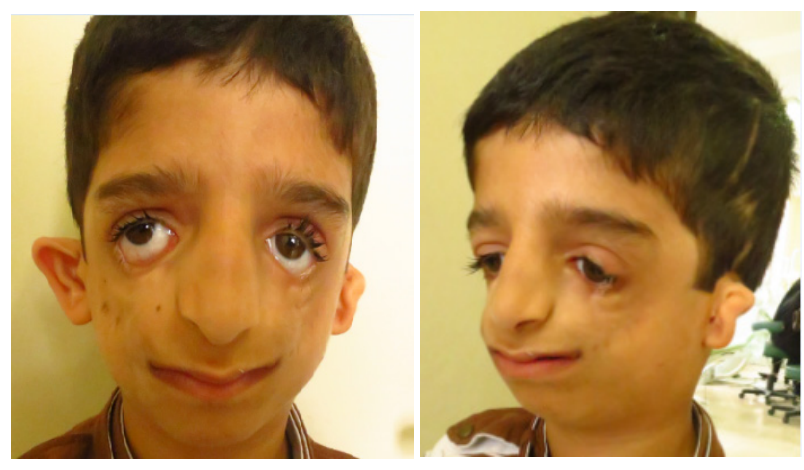

Figure 1. The clinical view of the 7-year-old boy with Treacher Collins syndrome

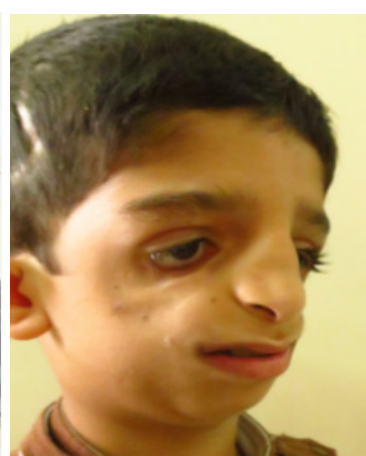

Journal of Pediatrics Review
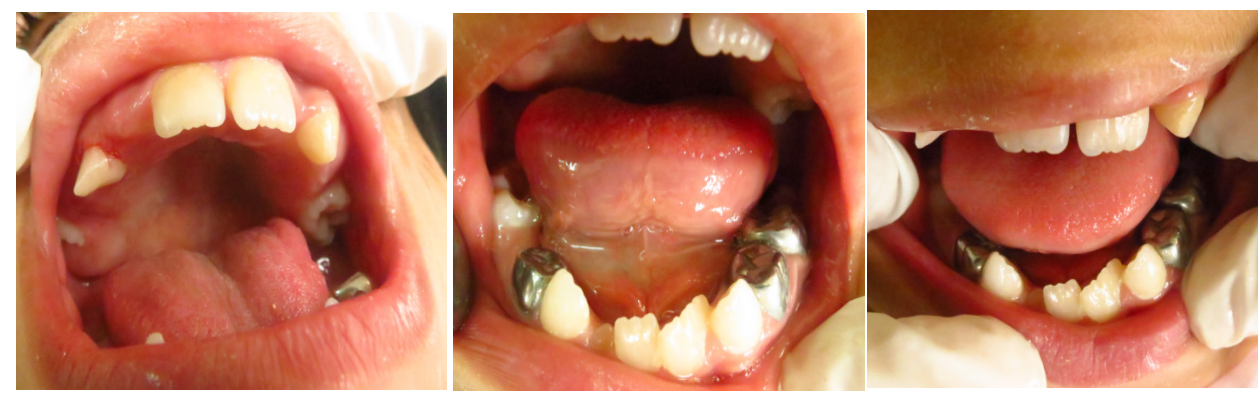

Figure 2. Intraoral photographs, show the dental condition after treatment

Journal of Pediatrics Review 
Table 1. Previous literature

\begin{tabular}{|c|c|c|c|c|}
\hline Writer(s) & $\begin{array}{c}\text { Year } \\
\text { of } \\
\text { Study }\end{array}$ & $\begin{array}{c}\text { Age } \\
\text { (Years Old) }\end{array}$ & Sex & Clinical and Radiographic Features \\
\hline
\end{tabular}

1

Shapira et al.

(18)

1996

7.5

Male

2

Eduardo et al.

[19]

2005

18

Female

Kasat and Baldawa (16)
2011

18
- No family history

- No consanguinity between the parents

- The mother used paroxetine (antidepressant drug of the SSRI type) 20 mg daily during the whole pregnancy

- He was considered to be small for gestational age

- Triangular face

- Long and thin hairs

- Hypertelorism

- Proptosis

- Downslant palpebral fissures

- Sparse eyelashes

- Malar hypoplasia

- Dysplastic, small and low-set ears

- Atretic External auditory canals - Micrognathia

- Unilateral choanal atresia

- No abnormality in Chromosomal analysis

- Normal visual abitity

- Bilateral hearing loss

- Bilateral unpneumatized mastoid bones and stenotic external auditory canals

- Pulmonary atresia, atrial septal defect, ventricular septal defect, and double-superior vena cava

- On the 30th day of life, the baby had sudden cardiac arrest and died.

- Antimongoloid slanting of the palpebral fissures

- Malar hypoplasia of the zygomatic arch - Mandibular hypoplasia

- Bilateral coloboma of the lower eyelids

- Malformations of auricular pinna

- Communication deficit and standard school performance

- Nasal obstruction

- Mouth breathing

- Anterior and posterior nasal septum deviation

- Bilateral choanal obstruction and choanal atresia

- Positive family history ( father and grandmather)

- Antimongloid slanting of the palpebral fissures with sparse eyelashes on the lower eyelid

- Malar prominence hypoplasia

- Micrognathia (maxilla appeared to be prognathic)

- 'Bird like' appearance

- Narrow high arched palate

proclination of maxillary incisors and there was spacing in the maxillary and mandibular anterior teeth

- Prominent antigonial notch

- Short ramus

- Hypoplasia of the mandible

- Proclined upper anterior teeth

- Steep occlusal plane

- Hypoplasia of zygomatic bone and maxillary sinus

- Hypoplastic cheeks,zygomatic arches and mandible

- Anti mongoloid slant to the eyes

- Colobomas of outer canthus of eyes

4 Kothari [20] $2012 \quad 6 \quad$ Male

- Small oral cavity \& airway with normal sized tongue and difficulty in eating food

- Concave lower border of mandible

- Convex profile

- Incompetent lips 


\begin{tabular}{|c|c|c|c|c|c|}
\hline & Writer(s) & $\begin{array}{c}\text { Year } \\
\text { of } \\
\text { Study }\end{array}$ & $\begin{array}{c}\text { Age } \\
\text { (Years Old) }\end{array}$ & Sex & Clinical and Radiographic Features \\
\hline 5 & $\begin{array}{c}\text { Mohan et al. } \\
\text { [21] }\end{array}$ & 2013 & 17 & Female & $\begin{array}{l}\text { - No history of consanguineous marriage } \\
\text { - Narrow face with mandibular hypoplasia along with prominent antigonial } \\
\text { notch } \\
\text { - Malar hypoplasia along with hypertrophy of both maxillary sinus walls } \\
\text { - antimongoloid slant of eyes } \\
\text { - The nose to appear very prominent } \\
\text { - Partial absence of lower eyelashes } \\
\text { - Coloboma of lower lateral eyelid } \\
\text { - Atresic canals of external ear } \\
\text { - Bilaterally External ear malformation in the form of a rudimentary pinna } \\
\text { - Absence of opening from the external to the internal ear } \\
\text { - Conduction deafness with } 50 \% \text { reduction in hearing } \\
\text { Presence of a tongue-shaped process of hair on the lateral side of the } \\
\text { face }\end{array}$ \\
\hline 6 & Delin et al. [3] & 2014 & Newborn & Male & $\begin{array}{l}\text { - No family history of congenital defects, especially facial anomaly } \\
\text { - Without consanguinity between the parents } \\
\text { - The mother used paroxetine (antidepressant drug of the SSRI type) } 20 \\
\text { mg daily during the whole pregnancy } \\
\text { - Triangular face with long and thin hairs } \\
\text { - Hypertelorism and proptosis } \\
\text { - Malar hypoplasia } \\
\text { - Sparse eyelashes } \\
\text { Dysplastic, small and low-set ears } \\
\text { - Mxternal auditory atretic canals } \\
\text { - Unilateral choanal atresia } \\
\text { Bilateral hearing loss } \\
\text { - Bilateral unpneumatized mastoid bones and stenotic external auditory } \\
\text { canals } \\
\text { - Pulmonary atresia, atrial septal defect, ventricular septal defect, and } \\
\text { double-superior vena cava } \\
\text { - On the 30th day of life, the baby had sudden cardiac arrest, and did not } \\
\text { respond to resuscitation. }\end{array}$ \\
\hline 7 & Renju et al. [4] & 2014 & 10 & Female & $\begin{array}{l}\text { - Positive family history (The child's father also had similar phenotypic } \\
\text { features like antimongoloid palpebral fissures; deficient malar promi- } \\
\text { nence and anterior open bite) } \\
\text { - Downward slanting of eyes } \\
\text { - Depressed zygomatic arches } \\
\text { - Deformed external ears } \\
\text { - Coloboma of lower eyelid } \\
\text { - Retruded chin giving ( bird-like appearance) } \\
\text { - Deviated nasal septum } \\
\text { - Limited mouth opening ( } 18 \mathrm{~mm} \text { ) } \\
\text { - Class III molar relationship with anterior open bite } \\
\text { - Crowding of maxillary and mandibular anterior teeth } \\
\text { - High arched palate with submucosal cleft } \\
\text { - With mouth breathing and tongue thrusting } \\
\text { - Low birth weight, frequent episodes of fever during childhood and } \\
\text { delayed speech } \\
\text { - Underdeveloped condylar and coronoid processes, hypoplastic zygomatic } \\
\text { arches and short rami } \\
\text { - Difficulties in swallowing and hearing and impaired vision } \\
\text { - Rbsence of middle ear on the right side and conductive hearing loss } \\
\text { - Decreased the ramal height and mandibular length }\end{array}$ \\
\hline
\end{tabular}




\begin{tabular}{lcccc}
\hline Writer(s) & $\begin{array}{c}\text { Year } \\
\text { of } \\
\text { Study }\end{array}$ & $\begin{array}{c}\text { Age } \\
\text { (Years Old) }\end{array}$ & Sex & Clinical and Radiographic Features \\
\hline
\end{tabular}

8 Sharma et al.
2016

\section{1 month}

Male

- The first child of a 22-year-old with non consanguinous marriage - No family history

- Hearing deficit as he did not turn his head to sound - There was a history of delayed crying at birth

- The skull was normal except for an open anterior fontanelle

- Bilaterally symmetrical but abnormal face characteristics - downwardslanting eyes

- Malar hypoplasia

- Mandibular hypoplasia (micrognathia)

- A large fishlike mouth (macrostomia) with a high arched palate

- Retropositioned tongue but no difficulty in feeding and swallowing

- Malformed and crumpled bilateral pinnae

- Right external auditory canal stenosis and left external auditory canal atresia

- Pectus carinatum and chest indrawing

- Vesicular breath sounds with prolonged expiration - Scaphoid abdomen

- Antimongoloid slant of the palpebral fissures

- Bilateral lower lid coloboma (lateral one third) with absence of eyelashes in the entire extent of the lower lids

- Congested inferior conjunctiva in both eyes with superficial haze of the inferior cornea(exposure keratopathy).

- Normal pupils in size with normal reaction to light

- Bilateral lower lid coloboma with exposure keratopathy

- With history of surgical correction of cleft palate when she was 3 years of age

- Asymmetry on left side of the face

- Increased inter-canthal distance - Frontal bossing

- Deficient/hypoplastic malar bones

- Prognathic anterior maxilla

- Short upper lip and incompetent lips

- Absence of mental groove and retrognathic mandible

- Deviation of nasal septum towards left side

9 Gopal S [23] $2016 \quad 18 \quad$ Female

- Deformity of the left ear with absence o left auditory canal, resulting in loss of hearing ability in the Left ear

- High arch palate with evidence of scar

- All the permanent teeth were fully erupted with multiple dental caries and andgeneralized enamel hypoplasia

- Crowding of lower anterior teeth

- Deformed uvula with the bifid morphology (under developed in the left side).

- Prominent antigonial notch on the left side

- Short ramus

- retrognathic mandible

- Hypoplasia of the left side of mandible and zygomatic bone

- Proclined upper anterior teeth

- Absence of consanguineous marriage

- Normal three siblings

- No family history

- Downward obliquity palpebral fissures (antimongoloid slants)

- Partially absence of lower eyelashes

- Flattening of Temporo-parietal on left side

- Mandible hypoplasia

- Protruding upper dentition

- Bilateral zygomatic and malar hypoplasia

- Narrow facial dimension and bird like-appearance to the face

- The external ears malformation

- Partial hearing loss (conductive type)

- A classic hair growth pattern on the cheek region on both sides

- Prominent antimongloid notch

- Elevated ramus-body angle and short ramus

- Dipping on right side and loss of glenoid fossa architecture and small condyle on both sides 


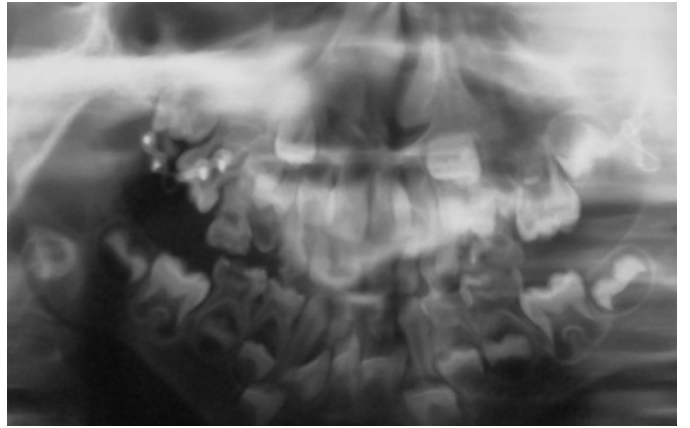

Journal of Pediatrics Review

Figure 3. The panoramic view of the dental condition before treatment

TCS cases. In individuals without an identified mutation in one of these genes, the genetic cause of the condition is unknown. Only $40 \%$ of the mutations are inherited, and the remaining $60 \%$ are de novo (8). The overall incidence of TCS is one in 50000 live births and affects both genders equally (6).

Most of the features of TCS are bilateral - meaning equally affecting both sides of body - and are already recognizable at birth, including hypoplasia of the facial bones (small and malformed jaw and malocclusion), external ear anomalies (inner ear malformations are rarely described) and conductive hearing loss, eye problems and loss of vision, strabismus, anisometropia, cleft palate, and airway problems which are often a result of mandibular hypoplasia and brachycephaly (9-13). Nasal deformities (large, beak-like nose with obstructed or small nasal passages), down-slanting eyes, few eyelashes, lower eyelid notching, eye abnormalities that might lead to loss of vision, high arched palate (9), coloboma of the upper lid, ocular hypertelorism (14), choanal atresia, macrostomia, preauricular hair displacement, absent or underdeveloped cheekbones and the floor and side wall of the eye socket, lower jaw that is often slanting and small, unusual hairline with hair growing across the cheek like a sideburn, malformed or underdeveloped and or prominent ears, middle ear effects leading to loss of hearing in some cases (9), and very small or missing thumbs (6) are some of the less frequent features of TCS.

Dental anomalies are seen in $60 \%$ of TCS patients, and consist of tooth agenesis (33\%), enamel deformities (20\%), and mal-positioned maxillary first molars (13\%). In some cases, dental anomalies in combination with mandibular hypoplasia result in malocclusion which can lead to problems with food intake and the ability to close the mouth (2). In addition, speaking difficulties and other communication problems are also present. Children with this syndrome have normal intelligence and grow up to be functional adults with normal life spans. The best therapeutic outcomes are therefore achieved with early intervention (6). The OMENS classification was developed as a comprehensive and stage-based approach to classify the disorder (15) into the complete (presenting all the known features), incomplete (less severe ear, eye, zygoma and mandibular abnormalities), abortive (only lower lid pseudo coloboma and zygomatic hypoplasia), unilateral (anomalies limited to only one side of the face), and the atypical (combined with other abnormalities not usually part of this syndrome) forms (16). Other diseases that have similar clinical features are acrofacial dysostosis, Nager syndrome, Miller syndrome, hemifacial microsomia and Goldenhar syndrome (17).

Our patient had a convex facial profile with a prominent dorsum of the nose above a retrusive lower jaw and chin. The eyes were characterized by an antimongoloid slant of the palpebral fissure resulting from coloboma and hypoplasia of the lower eyelids and lateral canthi, including partial absence of eyelid cilia. 'Tongue-shaped' processes of hair frequently extending into the pre-auricular region were observed. The external ears were malformed and malposed, and hearing was impaired. He presented the full expression of TCS with no familial history.

TCS has been described extensively in the scientific literature, with more than 250 reported cases (18). In this article, we reviewed 10 case reports of this syndrome (Table 1). Shapira (18) presented a case of a 7.5-yearold boy with fully expressed TCS. His four permanent molars needed restorations. Medical history of the child showed that he had four sessions of general anesthesia in the past 5 years; two sessions of surgical procedures for correcting facial defects (bone grafts to the orbital floor and correction of the antimongoloid obliquity of his eyes), and two sessions for dental treatment.

Eduardo et al. (19) reported an 18-year-old female patient with complaint of nasal obstruction and mouth breathing. She presented with antimongoloid slanting of the palpebral fissures, malar hypoplasia of the zygomatic arch, mandibular hypoplasia, bilateral coloboma of the lower eyelids and malformations of auricular pinna. She also had communication deficit and standard school performance. Diagnosis of choanal atresia was confirmed by nasofibroscopy. Postoperatively, the patient presented occasional nocturnal apnea, in spite of permeable choanae. Therefore, she underwent advanced mentoplasty, which was performed by the service's orthognathic surgical team, as well as uvulo- 
palatoplasty. The patient presented good evolution and improved breathing pattern after the operation, and no respiratory disorders were observed during follow-up. Kasat and Baldawa (16) reported an 18-year-old female with the chief complaint of forwardly placed upper anterior teeth. Family history revealed that her father and grandmother had typical signs of TCS.

On extra oral examination, she presented with antimongoloid slanting of the palpebral fissures with sparse eyelashes on the lower eyelid. There was hypoplasia of the malar prominence, and micrognathia was also evident. The maxilla appeared to be prognathic giving her face the 'bird like' appearance. Intraoral examination revealed narrow high arched palate. The maxillary incisors were proclined, and there was spacing in the maxillary and mandibular anterior teeth. Radiographs revealed prominent antegonial notch, short ramus, hypoplasia of the mandible, proclined upper anterior teeth, steep occlusal plane, hypoplasia of zygomatic bone and maxillary sinus. Kothari (20) reported a 6-year-old boy presenting with asymmetric facial features and difficulty in eating food due to hypoplastic cheeks, zygomatic arches and mandible, antimongoloid slant to the eyes, colobomas of outer canthus of eyes, small oral cavity and airway with normal sized tongue, concave lower border of mandible, convex profile, and incompetent lips.

Mohan et al. (21) reported a 17-year-old woman with hot and cold sensitivity in her left lower back tooth. An extraoral examination revealed a narrow face with mandibular and zygomatic hypoplasia along with antimongoloid slant of eyes. Mandibular hypoplasia caused the upper dentition to appear protruded. Malar hypoplasia resulted in a 'sunk-in' appearance temporally, causing the nose to appear very prominent. The patient's eyes were remarkable, and there was partial absence of lower eyelashes and coloboma of lower lateral eyelid. External ear malformation in the form of a rudimentary pinna was present bilaterally. In addition, the external ear canals were atresic with absence of opening from the external to the internal ear.

Conduction deafness with $50 \%$ reduction in hearing was also present. Another interesting feature was the presence of a tongue-shaped process of hair on the lateral side of the face. Intraoral examination revealed an anterior open bite and carious in the left lower first and second molars. This patient was the youngest of the four children born to parents with no history of consanguineous marriage. The radiographic investigations revealed mandibular hypoplasia along with prominent antegonial notch. Delin et al. (3) reported a newborn male infant whose mother had received no prenatal care. Both parents were unaffected, and there was no family history of congenital defects, especially facial anomaly. There was no consanguinity between the parents. The mother used $20 \mathrm{mg}$ paroxetine (antidepressant drug of the SSRI type) daily during the entire pregnancy. On physical examination, the infant was considered to be small for the gestational age. He had a triangular face with long and thin hairs, hypertelorism and proptosis, downslanted palpebral fissures, hypoplastic malar region, and sparse eyelashes. His ears were dysplastic, small and low-set, and external auditory canals were atretic, making it difficult to see the ear membranes. He also had micrognathia and unilateral choanal atresia.

Chromosomal analysis and eye exam showed no abnormalities. Audiological examination identified bilateral hearing loss. Bilateral un-pneumatized mastoid bones and stenotic external auditory canals were observed on temporal CT. Echocardiography showed pulmonary atresia, atrial septal defect, ventricular septal defect, and double-superior vena cava. The patient underwent modified BlalockTaussig (BT) shunt on the sixth day of life. He needed mechanical ventilation support for ten days. Unfortunately, on the 30th day of his life, the baby had sudden cardiac arrest and did not respond to resuscitation. Renju et al. (4) reported a 10-year-old girl with the chief complaint of decayed teeth. Examination revealed downward slanting of eyes, depressed zygomatic arches, sunken cheekbones, deformed external ears, coloboma of lower eyelids and retruded chin giving a bird-like appearance.

The nasal septum was deviated, and mouth opening was limited to $18 \mathrm{~mm}$, and the path of closure was deviated to the right side. Intraoral examination revealed Class III molar relationship with anterior open bite, crowding of maxillary and mandibular anterior teeth, high arched palate with submucosal cleft and deep dentinal caries in relation to teeth 75 and 36 . The child had the habit of mouth breathing and tongue thrusting. Her detailed case history revealed low birth weight, frequent episodes of fever during childhood and delayed speech. Orthopantomogram showed underdeveloped condylar and coronoid processes, hypoplastic zygomatic arches and short rami. Functional abnormalities included difficulties in swallowing and hearing, along with impaired vision. A subsequent ENT consultation revealed absence of middle ear on the right side and conductive hearing loss. 
The child's father also had similar phenotypic features like antimongoloid palpebral fissures, deficient malar prominence and anterior open bite. The cephalometric analysis showed reduced anterior cranial base length, ramal height and mandibular length. Sharma et al. (22) reported a 28-day-old male child who was brought to the ophthalmology outpatient department with a complaint of redness in both eyes for the past 10 days. It was not associated with any discharge from either eye. The patient was the first child of a 22-yearold woman who delivered at the same hospital at term. There was a history of delayed crying at birth. He was born of a non-consanguineous marriage and the pedigree analysis revealed no other affected member in the family. The developmental milestones were age appropriate except for hearing deficit as he did not turn his head to sound. He was breast fed and showed no difficulty in swallowing. The skull was normal except for an open anterior fontanelle. The facial characteristics were bilaterally symmetrical but abnormal. There were multiple facial dysmorphic features, including downward slanting eyes, malar hypoplasia, and mandibular hypoplasia. His pupils were normal sized with normal reaction to light.

The fundus examination was also normal. The infant was diagnosed with TCS with bilateral lower lid coloboma with exposure keratopathy. He was prescribed a topical antibiotic and a topical lubricant. He responded dramatically, with both conjunctival congestion and corneal haze disappearing after 3 days of follow-up. Gopal (23) presented an 18-year-old female patient with the chief complaint of pain in her right lower back tooth region for past 1 month. The patient had undergone surgical correction of cleft palate when she was 3 years old. Her facial profile revealed asymmetry on left side of the face, increased intercanthal distance, frontal bossing, deficient/hypoplastic malar bones, prognathic anterior maxilla, short upper lip, incompetent lips, absence of mental groove, and retrognathic mandible. Her ENT examination confirmed deviation of nasal septum towards left side and deformity of the left ear with the absence of left auditory canal, resulting in loss of hearing ability in the left ear. Intraoral examination revealed high arch palate with evidence of scar.

All the permanent teeth were fully erupted with multiple dental caries. The lower anterior teeth were crowded and generalized enamel hypoplasia was evident. The patient also presented with a deformed uvula with the bifid morphology (under developed in the left side). Radiographic survey with OPG and lateral cephalogram were performed, and OPG revealed prominent antegonial notch on the left side, short ramus, and hypoplasia of the left side of mandible. Lateral cephalogram revealed zygomatic bone and proclined upper anterior teeth and retrognathic mandible. Radiographic features provided a provisional diagnosis of TCS. Panta et al. (24) reported a 13-year-old boy whose complaint was unsatisfactory facial growth and forwardly placed upper front teeth. Family history revealed an absence of consanguineous marriage and all his three siblings were normal. The external ears were severely malformed, and hearing loss was partial (conductive type). A classic hair growth pattern was noticed towards the cheek region on both sides. Hypoplasia of mandible, upper anterior teeth protrusion and prominent antimongoloid notch were observed. Zygoma defect was bilateral, and classified as a minor type 1 defect. Significant changes were observed in mandibular parameters such as antegonial notching, and elevated ramus-body angle and short ramus. There was temporoparietal flattening on left side, dipping on right side, and loss of glenoid fossa architecture and small condyle on both sides. Since family history was negative, the cause was likely a de novo mutation involving one of the candidate genes of TCS.

The treatment of individuals affected by TCS needs a multidisciplinary approach and may involve the intervention of different professionals. The primary concerns in individuals with TCS are breathing and feeding problems, which are the consequence of the mandibular hypoplasia and obstruction of the hypopharynx by the tongue. A tracheostomy may even be necessary in some cases to maintain an adequate airway (25). Furthermore, a gastrostomy could be necessary to ensure an adequate caloric intake while protecting the airway. Surgery to restore a normal structure of the face is normally performed at defined ages, depending on the developmental stage (26).

TCS is an example of an autosomal dominant syndrome with incomplete penetrance and variable manifestations. An affected parent of either sex will transmit the defect to $50 \%$ of his or her offspring in accordance with the Mendel's laws of genetics. This emphasizes the importance of genetic counseling to individuals carrying relevant mutations. It is our responsibility as oral physicians to recognize this disorder and to provide close follow-up, appropriate therapy, and counseling. In addition, early diagnosis of TCS allows appropriate treatment of aesthetic and functional deficiencies in these patients. In fact, ameliorating the outward signs gives these patients the opportunity to have an improved social life. Patients with severe form of TCS 
usually undergo multiple major reconstructive surgeries that are rarely fully corrective, and stem cell therapy is unlikely to benefit the reconstructive repair of severe craniofacial malformations (16). Consequently, more research should be directed on the preventive aspects of this syndrome.

\section{Ethical Considerations}

\section{Funding}

This research did not receive any specific grant from funding agencies in the public, commercial, or not-forprofit sectors.

\section{Conflict of interest}

The authors declared no conflict of interest.

\section{References}

[1] Argenta LC, lacobucci JJ. Treacher Collins syndrome: Present concepts of the disorder and their surgical correction. World Journal of Surgery. 1989; 13(4):401-09. [DOI:10.1007/BF01660753]

[2] Da Silva Dalben G, Casta B, Gomide MR. Prevalence of dental anomalies, ectopic eruption and associated oral malformations in subjects with Treacher Collins syndrome. Oral Surgery, Oral Medicine, Oral Pathology, and Oral Radiology. 2006; 101(5):588-92. [PMID] [DOI:10.1016/j. tripleo.2005.07.016]

[3] Dinlen N, Zenciroglu A, Dilli D, Aydin D, Beken S et al. Treacher Collins syndrome with multiple congenital heart defects after paroxetine exposure: Case report. Genetic Counseling. 2014; 25(1):7-11. [PMID]

[4] Renju R, Varma BR, Kumar SJ, Kumaran P. Mandibulofacial dysostosis (Treacher Collins syndrome) : A case report and review of literature. Contemporary Clinical Dentistry. 2014; 5(4):532-4. [PMCID] [DOI:10.4103/0976-237X.142826]

[5] Posnick JC, Ruiz RL. Treacher Collins syndrome: Current evaluation, treatment, and future directions. The Cleft PalateCraniofacial Journal. 2000; 37(5):434. [DOI:10.1597/15451569(2000)0372.0.CO;2]

[6] Dixon J, Edvards SJ, Gladwin AJ, Dixon MJ, Loftus SK, Bonner $\mathrm{CA}$ et al. Positional cloning of a gene involved in the pathogenesis of Treacher Collins syndrome. Nature Genetics. 1996; 12(2):130-6. [DOI:10.1038/ng0296-130]

[7] Edwards SJ , Fowlie A , Cust MP , Liu DT , Young ID , Dixon MJ. Prenatal diagnosis in Treacher Collins syndrome using combined linkage analysis and ultrasound imaging. Jour- nal of Medical Genetics 1996; 33(7):603-6. [DOI:10.1136/ jmg.33.7.603]

[8] Splendore A , Jabs EW, Felix TM , Passos- Bueno R M. Parental origin of mutations in sporadic cases of Treacher Collins syndrome. European Journal of Human Genetics 2003; 11(9):718-22. [DOI:10.1038/sj.ejhg.5201029]

[9] Katsanis SH, Jabs EW. Treacher Collins syndrome [Internet]. 2012 [Updated 2012 August 30]. available from: https:// www.ncbi.nIm.nih.gov/books/NBK1532/

[10] Posnick J C. Treacher Collins syndrome: Perspectives in evaluation and treatment. Journal of Oral and Maxillofacial Surgery 1997; 55(10):1120-33. [DOI:10.1016/S02782391(97)90294-9]

[11] Trainor PA, Dixon J, Dixon MJ. Treacher Collins syndrome: etiology, pathogenesis and prevention. European Journa of Human Genetics 2009; 17(3):275-83. [DOI:10.1038/ ejhg.2008.221]

[12] Hertle RW, Ziylan S, Katowitz JA. Ophthalmic features and visual prognosis in the Treacher-Collins syndrome. British Journal of Ophthalmology 1993; 77(10):642-5. [DOI:10.1136/bjo.77.10.642]

[13] Masotti C , Ornelas C C , Splendore-Gordonos A , Moura R ,Félix TM , Alonso N, et al. Reduced transcription of TCOF1 in adult cells of Treacher Collins syndrome patients. BMC Medical Genetics 2009; 10(1):136. [DOI:10.1186/14712350-10-136]

[14] Marszałek B, Wójcicki P, Kobus K, Trzeciak WH. Clinical features, treatment and genetic background of Treacher Collins syndrome. Journal of Applied Genetics. 2002, 43(2):223-33. [PMID]

[15] Vento AR, LaBrie RA, Mulliken JB. The O.M.E.N.S classification of hemifacial microsomia. The Cleft Palate-Craniofacial Journal. 1991; 28(1):68-77. [DOI: 10.1597/1545-1569(1991)028<0068:tomens>2.3.co;2]

[16] Kasat VO, Baldawa R. Treacher Collins syndrome - A case report and review of literature. Journal of Clinical and Experimental Dentistry. 2011; 3:395-9. [DOI:10.4317/ jced.3.e395]

[17] Dixon MJ. Treacher Collins syndrome. Journal of Medical Genetics 1995; 32(10):806-8. [DOI:10.1136/ jmg.32.10.806]

[18] shapira J, Gleicher H, Moskovitz, Peretz B. Respiratory arrest in Treacher-collins syndrome: Implications for dental management: Case report. American Academy of Pediatric Dentistry. 1996; 18(3):242-4. [PMID]

[19] Andrade E C, Júnior VS , Didoni ALS, Freitas P Z, Carneiro AF, Yoshimoto FR. Treacher Collins syndrome with choanal atresia: a case report and review of disease features. Rev. Bras. Otorrinolaringol. 2005; 71(1):107-10. [DOI:10.1016/ S1808-8694(15)31296-9] 
[20] Kothari P. Treacher Collins Syndrome: A case report. WebmedCentral DENTISTRY. 2012; 3(1):WMC002902. [DOI: 10.9754/journal.wmc.2012.002902]

[21] Mohan RPS, Verma S, Agarwal N,Singh U. Treacher Collins syndrome: A case report. BMJ Case Reports. 2013. [DOI:10.1136/bcr-2013-009341]

[22] Reena Sharma, Brahmadeo Sharma, Meenu Babber, Sonali Singh, Gunjan Jain. Treacher Collins syndrome: A case report and review of ophthalmic features. Taiwan Journal of Ophthalmology. 2016; 6(4):206-9. [DOI:10.1016/j. tjo.2016.07.002]

[23] Gopal S, Kshatri JKS, Ramesh K. Treacher Collin Syndrome: A Clinical Case Report. International Journal of Research 2016; 8(5):31814-7.

[24] Panta P, Yaga US, Mengji A K, Radhika B, Swetha Rao M. Treacher Collins Syndrome - Case Report and Review. Oral Health and Dental Management. 2017; 16(1):1-3.

[25] Goel L, Bennur SK, Jambhale S. Treacher Collins Syndrome-A Challenge For Aaesthesiologists. Indian Journal of Anaesthesia. 2009; 53(4):496-500. [PMCID]

[26] Evans AK, Rahbar R, Rogers GF , Mulliken JB , Volk MS. Robin sequence: A retrospective review of 115 patients. International Journal of Pediatric Otorhinolaryngology 2006; 70(6):973-80. [DOI:10.1016/j.ijporl.2005.10.016] 